\title{
El relato de la transfiguración. Cristología alta y monoteísmo en Marcos*
}

\author{
César Octavio Carbullanca Núñez \\ Pontificia Universidad Católica de Chile, Centro de \\ Estudios de la Religión \\ http://orcid.org/0000-0002-9346-3543
}

RECIBIDO: 05-05-20. APROBADO: 07-09-21

Resumen: La búsqueda de un nuevo consenso en la cristología marcana choca con la opinión exegética que sostiene que el Evangelio de Marcos escaparía a la pretensión de una cristología alta. Además, el nuevo consenso fracasa con la opinión de que el Jesús histórico no habría asumido una identidad divina en el contexto monoteísta judío. El artículo, en contra de esta posición y asumiendo la opinión de J. Neusner, sostendrá que el angelomórfismo describe una categoría histórico-cultural que aporta elementos significativos para mostrar relatos de sujetos que se manifiestan en forma de seres humanos o de seres humanos que llegan a ser ángeles. Así, el relato de la transfiguración asume materiales que proceden de un tipo de judaísmo marginal de la Palestina del siglo II a. C. al I d. C., que posee categorías escatológicas dualista, visionaria y del envío de profetas angelomórficos. En continuidad con este judaísmo visionario, el relato de Mc 9,3-11 registra una experiencia visionaria de Jesús y los apóstoles, se discute que la fórmula $\omega ̋ \theta \eta$ está en función de mostrar una experiencia celeste con Elías y Moisés, en la cual la identidad de Jesús es revelada por el Padre como el Hijo amado, como sumo sacerdote adámico, superior a las figuras angelomórficas de Moisés y Elías, lo cual es coherente con diversos relatos del Hijo del Hombre marcano. El relato muestra, en continuidad con estos antecedentes judíos, que la figura del Hijo del Hombre asume funciones escatológicas aplicadas a Yahveh y en discontinuidad con aquellas expresa que la autoridad del Hijo del Hombre está ya en su condición terrena por sobre las figuras de Elías y Moisés y de los ángeles y demonios, y sometido al Padre.

Palabras ClaVe: Cristología alta; escatología; profeta; transfiguración; mística; angelomorfismo; resurrección; parusía; Hijo; Hijo del hombre.

*Artículo de investigación.

a Autor de correspondencia. Dirección electrónica: ccarbull@uc.cl; cesarcarbullanca@gmail.com 


\section{The Narration of the Transfiguration. High Christology and Monotheism in Mark}

AвSTRACT: The search for a new consensus in Mark's Christology collides with the exegetical opinion that the Gospel of Mark would escape the claim of a high Christology. Furthermore, the new consensus fails with the opinion that the historical Jesus would not have assumed a divine identity in the Jewish monotheistic context. The article, contrary to this position and assuming the opinion of J. Neusner, will maintain that angelomorphism describes a historical-cultural category that contributes significant elements to the stories of subjects that manifest in the form of human beings or human beings who become angels. In this way, the account of the transfiguration assumes materials that come from a type of marginal Judaism in Palestine from the second Century B. C. to I A. D., which has dualistic, visionary and eschatological categories of angelomorphic prophets. In continuity with this visionary Judaism, the account of Mk 9:3-11 records a visionary experience of Jesus and the apostles, in which it is argued that the formula $\omega \not \phi \theta \eta$ is in function of showing a heavenly experience with Elijah and Moses in which the identity of Jesus is revealed by the Father as the beloved Son as the adamic high priest, higher to the angelomorphic figures of Moses and Elijah-consistent with various accounts of the Mark's Son of Man. The story shows, in continuity with these Jewish antecedents, that the figure of the Son of Man assumes eschatological functions applied to Yahweh and, in discontinuity with them, expresses that the authority of the Son of Man is already in his earthly condition above the figures of Elijah and Moses, and of angels and demons, and submitted to the Father.

Key Words: High Christology; Eschatology; prophet; transfiguration; mystic; Angelomorphism; Resurrection; parusia; Son; Son of man.

\section{CÓMO CITAR:}

Carbullanca, César. "El relato de la transfiguración. Cristología alta y monoteísmo en Marcos". Theologica Xaveriana (2021): 1-33. https://doi.org/10.11144/javeriana.tx71.rtcamm

\section{RECONOCIMIENTO}

El presente artículo se inscribe en el proyecto Fondecyt Regular 2018, N. ${ }^{\circ}$ 280788. Investigador responsable: Luis Bahamondes (UAH); coinvestigador: César Carbullanca (PUCCh). 


\section{Introducción}

La antigua convicción sobre las primeras cristologías que señalaba que estas se habrían desarrollado en el contexto de las religiones paganas comienza a ceder a nuevas maneras de enfrentar la emergencia de fe cristiana, ahora en relación con el monoteísmo judío. Es necesario decir que el estudio de los antecedentes sobre una cristología alta o angelomórfica se remontan a la Antigüedad, en opinión de Ch. Gieschen, y a partir de 1940 reviven los estudios de cristología angelomórfica ${ }^{1}$, como afirman L. W. Hurtado², A. Segal ${ }^{3}$ y Chr. Rowland ${ }^{4}$, quienes están contextualizados por una sensibilidad y una perspectiva nuevas, e investigan el monoteísmo judío, así como aspectos hasta ahora no estudiados, de tal manera que investigadores como A. Chester ${ }^{5}$, P. G. Davis ${ }^{6}$, R. T. France $^{7}$ y L. Hurtado ${ }^{8}$ han insistido en la necesidad de nuevas aproximaciones para el estudio de cristología neotestamentaria.

Así las cosas, la propuesta de L. Hurtado y otros más acerca de la devoción a Jesús como factor nuclear para la emergencia del biteísmo cristiano ha impactado en el mundo de los estudios cristológicos. Andrew Chester, Crispin Fletcher-Louis y Larry Hurtado hablan de una explosión en la investigación especializada sobre la primitiva cristología ${ }^{9}$, que pide un nuevo consenso respecto de la cuestión de la alta cristología ${ }^{10}$.

Es importante atender que la relación de los estudios de los antecedentes judíos de una cristología alta o "angelomórfica" y su impacto en escritos cristianos tiene directa relación con lo que entendemos por judaísmo monoteísta y en la discusión por la terminología empleada; es decir: hoy solo se puede aportar a este nuevo consenso por medio de una nueva consideración metodológica entre cultura y cristología. Así lo señala R. Bauckham; esta aproximación lleva a postular que la cuestión del

${ }^{1}$ Gieschen, Angelomorphic Christology. Antecedents \& Early Evidence, 17.

${ }^{2}$ Hurtado, One God, One Lord. Early Christian Devotion and Ancient Jewish Monotheism, 99; Hurtado, "Fashions, Fallacies and Future Prospects in New Testament Studies", 1-26; véase también a Hurtado, How on Earth did Jesus Become a God? Historical Questions about Earliest Devotion to Jesus; Hurtado, God in the New Testament; Hurtado, "Early High Christology': A Recent Assessment of Scholarly Debate".

${ }^{3}$ Segal, Two Powers in Heaven: Early Rabbinic Reports about Christianity and Gnosticism, 266.

${ }^{4}$ Véase a Rowland y Morray-Jones, The Mystery of God. Early Jewish and the New Testament.

${ }_{5}^{5}$ Chester, Messiah and Exaltation. 119-120.

6 Davis, "Divine agents, mediators, and New Testament Christology", 479.

7 Ibíd., 479; France, "Development in New Testament Christology", 4-9.

${ }^{8}$ Hurtado, "Fashions, Fallacies and Future Prospects in New Testament Studies", 1-26.

9 Hurtado, One God, One Lord. Early Christian Devotion and Ancient Jewish Monotheism, 12.

${ }^{10}$ Chester, "High Christology-Whence, When and Why?", 22-50. 
"monoteísmo y cristología fueron necesariamente relacionados uno al otro en la comprensión de la identidad de Jesús desde sus comienzos" ${ }^{11}$.

El nuevo consenso se ha concentrado de manera particular en textos paulinos, joánicos y en el libro del Apocalipsis, y su discusión en textos sinópticos ha sido menor ${ }^{12}$. Estudios referidos a los sinópticos, como el presentado por J. R. Kirk, quien muestra la identidad de Jesús como agente escatológico que realiza "funciones divinas", evitando hablar de Cristo en términos sustancialistas ${ }^{13}$.

En relación con la búsqueda de una cristología alta en el Evangelio de Marcos han aparecido diversos trabajos. Por supuesto existen autores como Michel Kox, quienes sostienen que Marcos escapa a este paradigma de una cristología alta ${ }^{14}$. Aunque cada vez, de manera creciente, autores como Adela Yarbro, Marcus Throup, Daniel Johansson y otros connotados estudiosos abogan por la existencia de una cristología alta en $\operatorname{Marcos}^{15}$.

El mismo L. Hurtado estudia el tema, señalando el interés de Marcos por mostrar la superioridad y significado trascendente o divino de Jesús ${ }^{16}$; no obstante, respecto de la figura del Hijo del Hombre, Hurtado -a diferencia de Fletcher-Louis- no considera este un aspecto significativo para una cristología alta en Marcos; otros intentos, como el estudio de M. Throup sobre relatos de milagros y exorcismos, sostiene que "Marcos pretende alguna forma de una identidad divina para Jesús" ${ }^{17}$. Kevin Sullivan estudia la relación de ángeles y seres humanos en algunos textos marcanos, como Mc 9,3-11; 14,51-52, y señala -en relación con Mc 9,3-11- que "algunos aspectos de la transfiguración apoyan una interpretación angelomórfica ${ }^{18}$.

\footnotetext{
${ }^{11}$ Bauckham, "Monotheism and Christology in the Gospel of John", 149.

${ }^{12}$ Ibíd., 148.

${ }^{13}$ Véase a Kirk, Daniel, A Man Attested by God: The Human Jesus of the Synoptic Gospels.

${ }^{14}$ Kok, "Marking a Difference: The Gospel of Mark and the 'Early High Christology' Paradigm”, 102-124.

${ }^{15}$ Throup, "Mark's Jesus, Divine? A Study of Aspects of Mark's Christology with Special Reference to Hebrew Divine Warrior Traditions in Mark, and in Relation to Contemporary Debates on Primitive Christology"; Collins, Mark, 260-333; Gathercole, The Pre-existent Son: Recovering the Christologies of Matthew, Mark and Luke, 62-64 ; Marcus, Mark 1-8. A New Translation with Introduction and Commentary, 432; Johansson, "Jesus and God in the Gospel of Mark: Unity and Distinction", 6-15, presenta una panorámica de las diversas formulaciones a lo largo del siglo XX; Watts, The Influence of the Isaianic New Exodus on the Gospel of Mark, 161-162; Watts, Christology and Discipleship in the Gospel of Mark.

${ }^{16}$ Hurtado, Señor Jesucristo. La devoción a Jesús en el cristianismo primitivo, 328-362.

${ }^{17}$ Throup, “Mark's Jesus, Divine? A Study of Aspects of Mark's Christology with Special Reference to Hebrew Divine Warrior Traditions in Mark, and in Relation to Contemporary Debates on Primitive Christology", 214.

${ }^{18}$ Sullivan, Wrestling with Angels. A Study of the Relationship between Angels and Humans in Ancient Jewish Literature and the New Testament, 115.
} 
Nicholas Perrin sostiene que "el Evangelio de Marcos está interesado principalmente no solo con una nueva comunidad como nuevo templo, sino también en Jesús como nuevo sumo sacerdote" ${ }^{19}$. También L. Schiavo afirma que el mito del combate escatológico está presente en el relato de Marcos como combate escatológico ${ }^{20}$, lo cual presupone la existencia de ángeles guerreros, categoría en la que se enumeran a Miguel, al Hijo del Hombre y a Melquisedec. Johansson afirma que probablemente el relato de la transfiguración "puede sugerir que Jesús es presentado como un ángel de YHWH"21.

\section{Objetivo y criterios}

En relación con el relato de la transfiguración marcano, diversos autores $-\mathrm{A}$. Chester ${ }^{22}$, M. Öhler ${ }^{23}$, J. Marcus ${ }^{24}$ y C. Fletcher-Louis- sostendrán opiniones respecto de la existencia de una cristología alta. Queremos subrayar la opinión de C. Fletcher-Louis, quien afirma sobre el relato de transfiguración lucano:

Lucas quizás esperaba diferenciar esta transfiguración [la de Jesús] de la acontecida a Enoch, Moisés y otros [...] Jesús no experimenta una transformación en una nueva identidad (temporal) por la transfiguración. Más bien, este es la revelación de una identidad que él ya ha poseído. ${ }^{25}$

Aunque está referido al relato lucano, nosotros tendremos en cuenta la reflexión de C. Fletcher-Louis, quien dice que el concepto de identidad postulado no tiene relación con un concepto psicológico sino mítico de identidad, el cual afirma la creencia en un alter ego celeste o en un tipo de identidad funcional del sujeto histórico. En otros términos, la posición de C. Fletcher-Louis respecto del relato de la transfiguración lucano no apunta a un modelo ascensional de transformación del Justo en ángel, sino a un modelo descendente relativo a un origen angelomórfico de Jesús semejante al que también se menciona de Juan el Bautista (Mc 1,2; 11, 28-33; y

${ }^{19}$ Perrin, "Jesus as Priest in the Gospels", 86.

${ }^{20}$ Schiavo, Anjos e Messias. Mesianismo judaicos e origen da cristología, 85.

${ }^{21}$ Johansson, "Jesus and God in the Gospel of Mark: Unity and Distinction”, 211.

${ }^{22}$ Chester, Messiah and Exaltation. Jewish Messianic and Visionary Traditions and New Testament Christology, 80 .

${ }^{23}$ Öhler, "Die Verklarung (Mk 9,1-8): Die Ankunft der Herrschaft gotters auf der erde”, 216.

${ }^{24}$ Marcus, Mark 8-16. A New Translation with Introduction and Commentary, 640.

${ }^{25}$ Fletcher-Louis, Luke-Acts: Angels, Christology and Soteriology, 49. 
Jn 1,6.7.25-27). Esta perspectiva la sigue R. Bauckham, quien señala "la más temprana cristología fue ya la cristología más alta” ${ }^{26}$.

Así las cosas, nuestro estudio se sitúa en la discusión sobre las formulaciones de las primeras cristologías en el contexto de las diversas experiencias del monoteísmo judío. Autores como Bauckham y Casey han puesto el acento en las notas características del monoteísmo judío; sin embargo, nos parece que estos intentos consideran el monoteísmo judío como una entidad homogénea y simple, y no integran de manera suficientemente los diversos judaísmos existentes durante el siglo I, de tal manera que tampoco integran el dualismo presente en algunos a corrientes judías, como la estratificación de seres entre el cielo y la tierra.

Aquella formulación del monoteísmo es demasiado general y se requiere una comprensión que tenga en cuenta los diversos modelos ideológicos que dan cuenta de los variados judaísmos del siglo I. En este mismo tenor, Fletcher-Louis asegura que, luego de la propuesta de L. Hurtado, estamos obligados a un estudio "más cuidadoso de los cambios cristológicos entre el segundo y tercer estado del modelo (aportado por Hurtado)" ${ }^{27}$.

Así, el presente artículo tiene por objeto demostrar la existencia de una cristología alta, dando algunos aspectos de esta cristología, entendida como el traspaso de funciones escatológicas al Hijo del Hombre, producto de su autoridad de Hijo, y mostrará lo siguiente:

- Primero, que el relato asume categorías cosmológicas dualistas y expectativas sobre el profeta escatológico entendido de manera angelomórfica, ya presente en diversos textos del judaísmo.

- Segundo, que el relato de la transfiguración muestra la identidad y autoridad adámica del Hijo del Hombre, expresado por un lado en la superior respecto de la identidad angelomórfica de Elías y Moisés, y por otro, relación con la ignorancia de los discípulos.

- Tercero, que la transfiguración no es un relato traspuesto de lugar, sino una experiencia visionaria de Jesús con sus discípulos que da cuenta de la filiación divina actual del Hijo del Hombre.

Desde un punto de vista metodológico se ha logrado comprender que la pesquisa por un nuevo consenso pasa por alcanzar un nuevo concepto de texto que

\footnotetext{
${ }^{26}$ Bauckham, Jesus and God of Israel. God Crucified and Other Studies on the New Testament's Christology of Divine Identity, 8.

${ }^{27}$ Fletcher-Louis, "A New Explanation of Christological Origins. A Review of the Work of Larry Hurtado", 176.
} 
incluye el uso de la memoria cultural como productora de textos ${ }^{28}$, y por el abandono de conceptos y paradigmas metafísicos ajenos a la cultura judía del siglo I. Esto no quiere decir la renuncia a estudiar expresiones o textos que muestran una cristología alta desde categorías anacrónicas; más bien significa la pretensión de estudiar esta identidad trascendente mediante un lenguaje propio de aquella cultura.

En otras palabras, grupos marginales o sectarios produjeron textos que comprendían el monoteísmo judío como parte de una cosmovisión dualista que integraba, tanto la existencia de revelaciones actuales como la realización del eschaton por medio ángeles, profetas y mesías trascendentes, comprometiendo así -en opinión de otras corrientes- la validez de las instituciones y la integridad del judaísmo.

Expliquemos en detalle este punto. Como se verá, la discusión depende de lo que entendamos por judaísmo. G. Boccaccini ha sistematizado las diversas comprensiones sobre el judaísmo ${ }^{29}$, las cuales exponemos esquemáticamente así:

1. Modelo minimalista (E. Sanders): el judaísmo se caracteriza por un común denominador teológico llamado "nomismo de la alianza"

2. Modelo evolutivo (L.Schiffman): acepta el dinamismo y la diversidad de judaísmo. Este es el resultado de una continua evolución ideológica que integra la diversidad, la discontinuidad y el conflicto.

3. Modelo étnico (Sh. Cohen): muestra escepticismo respecto de la búsqueda de una unidad del judaísmo desde el punto de vista ideológico y postula más bien una solidaridad étnica. Lo hebraico del etnos judaico no está dado en términos racionales o genéticos sino en términos de identidad cultural y nacional.

4. Modelo de diversidad (J. Neusner): lo característico del judaísmo es su carácter fragmentario; es decir, nunca ha existido un judaísmo sino diversos judaísmos, diferentes sistemas ideológicos en competencia entre sí.

\footnotetext{
${ }^{28}$ Horsley, “Jesus-in-context: A Relational Approach”, 207-239, en especial, 237.

${ }^{29}$ Boccaccini, I Giudaismi del Secondo Tempio. Da Ezejiele a Daniele, 20-27.
} 
Esta discusión sobre el judaísmo explica que diferentes autores -por ejemplo, M. Casey ${ }^{30}$, M. Kok ${ }^{31}$, L. Fletcher ${ }^{32}$, R. Bauckham ${ }^{33}$, P. G. Davies ${ }^{34}-$, al sostener una posición crítica a la propuesta de L. Hurtado conciben el judaísmo como un fenómeno que aceptaba seres intermedios, y afirman la necesidad de hablar de la función de estos seres intermedios más que de hipóstasis, entidades o estatu ${ }^{35}$; sobre todo autores como R. Bauckham, M. Casey y G. Theissen harán notar sus diferencias. Así, por ejemplo, M. Casey sostiene que el judaísmo del siglo I tuvo una identidad caracterizada por ocho aspectos fundamentales: etnicidad, escritura, monoteísmo, circuncisión, sábado, observación, leyes de alimentos, leyes de pureza, fiestas mayores ${ }^{36}$. Por otra parte, G. Theissen ${ }^{37}$ afirma que el judaísmo en cuanto religión es un sistema cultural semiótico que contempla tres aspectos: el mito, rito y la ética.

Nuestro estudio postulará que la relación entre el judaísmo y la comunidad marcana se comprende mejor en la perspectiva estudiada por J. Neusner ${ }^{38}$. Consideramos que el cristianismo emerge en el contexto de una fractura social del judaísmo. El Evangelio de Marcos se produce en medio de esta fragmentación, y el relato de la transfiguración se comprende mejor contextualizado como producto de categorías propias de un judaísmo marginal de la Palestina del siglo II a. C. al siglo I de nuestra era.

\section{Relato de la transfiguración}

\section{Estructura del relato y género}

La cuestión redaccional es compleja, y ya desde el comienzo del estudio de las formas se tomaron diversas posiciones sobre la estructuración del relato ${ }^{39}$.

\footnotetext{
${ }^{30}$ Casey, "Lord Jesus Christ: A Response to Professor Hurtado", 83-96; véase a Casey, From Jewish Prophet to Gentile God.

${ }^{31}$ Kok, "Marking a Difference: The Gospel of Mark and the 'Early High Christology' Paradigm", 102-124.

${ }^{32}$ Fletcher-Louis, "A New Explanation of Christological Origins. A Review of the Work of Larry Hurtado", 161-205; Fletcher-Louis, Jesus Monotheism. Vol. 1: Christological Origins: The Emerging Consensus and Beyond, 65ss.

${ }^{33}$ Bauckham, "Paul's Christology of Divine Identity".

${ }^{34}$ Davis, "Divine agents, mediators, and New Testament Christology", 479-503.

${ }^{35}$ Ibíd., 481.

${ }^{36}$ Casey, From Jewish Prophet to Gentile God, 12.

${ }^{37}$ Theissen, A Theory of Primitive Christian Religion, 41-60.

${ }^{38}$ Neusner, The Judaism the Rabbis Take for Granted, 12.

${ }^{39}$ Öhler, "Die Verklarung (Mk 9,1-8): Die Ankunft der Herrschaft gotters auf der erde”, 199.
} 
R. Bultmann sostenía que 9,1 en su origen continuaba en el v. 11, y su formación estaría en los debates de la comunidad ${ }^{40}$; igualmente, que el relato de la transfiguración habría sido, en su origen, una historia de apariciones del Resucitado traspuesta de lugar. En la actualidad, esta misma posición es defendida, brillantemente, por W. Schmithalts ${ }^{41}$.

Nosotros sostendremos que el Evangelio de Marcos nunca tuvo un relato de apariciones, pues fue redactado en el contexto de la inminente parusía.

E. Lohmeyer propuso una interpretación simbólica, en la que se distinguen dos fuentes ${ }^{42}$ : una leyenda basada en tradiciones judías, 9, 4. 6. 7; y la otra, el v. 3, que reflejaría una visión de los misterios helénicos ${ }^{43}$.

U. Müller distingue dos relatos: el primero es vv. 2c-6.8; y el segundo, vv. 2a.b. 7(9); y considera que "aquí hay un primitivo material el cual se retrotrae a Jesús”"44.

Öhler postula vv. 2c, 3-4.5b, 7.8 ${ }^{45}$ e integra 9, 1 al relato ${ }^{46}$.

E. Schweizer señala que el v. 9, con 11-13, no tienen nada que ver en el orden presentado $^{47}$, y propone que los vv. 11-13 deben ir con el v. 1, intercalando los vv. 2-8 y 9 .

R. Pesch considera todo el relato 9,1-13 como unidad, y afirma que hay que comprenderlo en su totalidad por la mezcla de motivos que presenta ${ }^{48}$. En consecuencia, el relato presenta un relato fragmentario en tensión compuesto por varias tradiciones ${ }^{49}$ premarcanas que testimonian la creencia en una experiencia visionaria-mística de Jesús con sus discípulos semejante a la descrita en textos apocalípticos, articulado con otras expresiones posteriores de una fe pospascual.

Ciertamente la mención de Elías en el relato, en los vv. 2-3 y 9-13, corresponde a tradiciones diversas; en la primera no se presupone el regreso de ambos sino tan solo del ascenso y transformación celeste. El estilo fragmentario del Evangelio marcano se aprecia por ejemplo en que encontramos dos fórmulas legitimadoras del profeta

${ }^{40}$ Bultmann, Historia de la tradición sinóptica, 180.

${ }^{41}$ Schmithals, "Der Markusschluß, die Verklarungsgeschichte und die Aussendung der Zwölf”, 379-411.

${ }^{42}$ Lohmeyer, "Die Verklärung Jesu nach dem Markus-evangelium”, 185-215.

${ }^{43}$ Ibíd., 185-215; Holzmeister, "Einzeluntersuchungen über das Geheimnis der Verkllärung Christi”, 200-210.

${ }^{44}$ Müller, "Die Christologische Absicht des Markusevangeliums und die Verklärungsgeschichte”, 60-61.

${ }^{45}$ Öhler, "Die Verklarung (Mk 9,1-8): Die Ankunft der Herrschaft gotters auf der erde”, 201.

46 Ibíd., 215.

${ }^{47}$ Schweizer, Das Evangelium nach Markus, 99.

${ }^{48}$ Pesch, Das Markusevangelium II, 71; Pesch y Schnackenburg (eds.), Jesus und der Menschensohn 174.

${ }^{49}$ Jeremias, Theology of New Testament, 37. 
escatológico: la primera, la fórmula $ڤ ̋ \phi \eta \eta$, entendida como fórmula de legitimación en Mc 9,4, empleado luego de la resurrección del Señor; y la segunda, la expresión

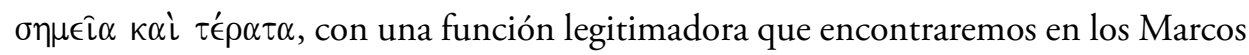
para referirse a las señales del último profeta y seudo mesías (Mc 8,12; 13:4.22; 16, 17-22; Lc 11,29), según Flavio Josefo (Ant 20, 8, 6; 20,50.1) .

Desde un punto de vista del género y de la terminología, el relato muestra paralelos con otras experiencias de profetas y místicos judíos que tienen una visión, ascienden al cielo, son transformados y-de manera representativa al grupo de elegidos o efectiva- padecen en su cuerpo a la espera de su exaltación (Parábolas de Enoch 70-71; Asc. Is 9,11). No hace mucho, el relato era calificado por R. Bultmann ${ }^{50}$ y por V. Taylor como "leyenda" ${ }^{1}$; para M. Dibelius se trata de una epifanía ${ }^{52}$; otros-como K. Berger- lo clasifican como una visión ${ }^{53}$. La propuesta que E. Lohmeyer es la de una interpretación simbólica ${ }^{54}$. Por otra parte, W. Grundmann no lo considera leyenda ni reflexión teológica, sino lo califica de Schul-oder Streitgespräch ${ }^{55}$, mientras que J. Gnilka lo ve como una entronización ${ }^{56}$.

Finalmente, otros se decantan por la descripción del texto con rasgos midrásicos; por ejemplo, algunos -como R. Pesch-ven en 9,1-13 una unidad. Pesch sostiene que Mc 9,9-13 “originariamente es el desglose de la escena apocalíptica-epifánica" M. Öhler deduce que la falta de términos decisivos relativos al ascenso al cielo muestra que el relato no pertenece al género ${ }^{58}$, y esto expresa que la visión representa la venida del Reino de Dios sobre la tierra. Sin embargo, esta es una comprensión equivocada, pues visiones y ascensos son equivalentes en no pocos textos apocalípticos judíos, y en algunos textos constituyen una secuencia: el ascenso es seguido de la visión; en otros, la visión precede al ascenso o al viaje a lugares remotos; y en otros más solo es mencionada la visión. En todos ellos se trata del conocimiento de los secretos divinos que legitiman la misión del visionario ${ }^{59}$.

\footnotetext{
${ }^{50}$ Bultmann, Historia de la tradición sinóptica, 318-319.

${ }^{51}$ Taylor, El Evangelio de Marcos, 101-102; Vielhauer, Historia de la literatura cristiana primitiva, 324-326.

52 Dibelius, Die Formgeschichte des Evangeliums, 276.

${ }^{53}$ Berger, Formgeschichte des Neuen Testaments, 284; Grundmann, Das Evangelium nach Markus, 237.

${ }^{54}$ Lohmeyer, “Die Verklärung Jesu nach dem Markus-evangelium”, 185-215.

${ }_{55}$ Grundmann, Das Evangelium nach Markus, 242.

${ }^{56}$ Gnilka, El Evangelio de Marcos II, 36.

${ }^{57}$ Pesch, Das Markusevangelium II, 71.

${ }^{58}$ Öhler, "Die Verklarung (Mk 9,1-8): Die Ankunft der Herrschaft gotters auf der erde", 215.

${ }^{59}$ Is 6,1; Dn 7,2; Ez 11,24 Mc 1,10; 9,2-4 Mc 14:62; Hch 7,1.55-56; de manera evidente en 4Q213a (4QAramaic Levi) fr. 1col. II, 15; 4Q213b 4QAramaic Levic; Ap 4, 1-2; 1 Enoch 14, 839,3-4.
} 


\section{Dualismo cósmico y alter ego}

Respecto de los antecedentes judíos sobre el culto y devoción a figuras intermedias, la cuestión metodológica es importante para establecer la relación entre literatura e imaginario social. Así, por ejemplo, L. Hurtado sostiene que la devoción a Jesús en el Nuevo Testamento no es una cuestión de imágenes, como sería el caso de la adoración de Adán, en la "Vida de Adán y Eva" (12-16), sino una cuestión de un patrón completo de comportamiento religioso ${ }^{60}$. Tal planteamiento me parece apresurado, pues presupone que el texto "Vida de Adán y Eva" es considerado solo como literatura. Es necesario considerar el texto en una base cultural más amplia; esto es, en este texto, como en otros, no se trata de ideas o de literatura, sino de imaginarios culturares que circulan fragmentariamente durante esta época y que implican una praxis social de diversos tipos de judaísmos.

Desde un punto de vista de las creencias culturales, el Evangelio de Marcos hay que considerarlo dentro de las coordenadas del monoteísmo judío, entendido este como una realidad plural, diversa, que incluye la creencia de un dualismo cósmico ${ }^{61}$ así como un orden jerárquico de seres ${ }^{62}$.

Podemos comprobar, en tres relatos de exorcismos del Evangelio que poseen como característica el dialogo de Jesús con espíritus inmundos (Mc 1,24-25; 5, 7-10 Mc 9,25-26), tres elementos centrales, a saber: (1) solo Jesús dialoga con seres humanos y con seres espirituales; (2) los espíritus inmundos y enviados de Dios conocen la identidad celeste de Jesús; (3) reflejan una escatología de presente ${ }^{63}$.

Esta misma visión dualista de la realidad aparece en relatos como Mc 1,11; 9,4-5; 8,38; 14,64; y 16,6. A nuestro parecer, ello refleja, tanto una identidad oculta que mueve el relato como una estructura literaria y cultural de dos niveles sobre la cual el relato de Marcos está diseñado. Los textos ya citados -específicamente Mc 9,4-5, “y les apareció Elías con Moisés, y estaban hablando con Jesús" - muestran este dualismo cósmico perteneciente al monoteísmo judío, por lo que es errado introducir categorías sustancialistas como hacen Öhler ${ }^{64}$ y Heil ${ }^{65}$.

\footnotetext{
${ }^{60}$ Hurtado, Señor Jesucristo. La devoción a Jesús en el cristianismo primitivo, 61. El motivo también se encuentra en 2Enoch 9,16-23; Sefer hekhalot 4,7-9

${ }^{61}$ Marcus, El Evangelio de Marcos (Mc 8-16), 1281-1293.

${ }^{62}$ Hengel, "Christological Titles in Early Christianity", 438.

${ }^{63}$ Theissen, El Jesus historico, 293.

${ }^{64}$ Öhler, "Die Verklarung (Mk 9,1-8): Die Ankunft der Herrschaft gotters auf der erde", 197-217, en especial 204.

${ }^{65}$ Heil, The Transfiguration of Jesus: Narrative Meaning and Function of Mark 9:2-8, Matt 17:1-8 and Luke 9:28-36, 92-93.
} 
Por ello, no es casual que diversos investigadores -J. Vanderkam ${ }^{66} \mathrm{o} \mathrm{J}$. Collinshan hecho notar que múltiples textos neotestamentarios se acercan al planteamiento de una escatología dualista presente en textos apocalípticos judíos. La existencia de este dualismo cósmico explica que sujetos escatológicos asciendan a los cielos, hablen con ángeles, o desciendan a la tierra con una misión; e incluso que determinados sujetos tengan una doble identidad celeste.

En este último punto, investigadores como C. Fletcher-Louis ${ }^{67}$, A. Orlov ${ }^{68}$, R. Elior ${ }^{69}$, K. Koch $^{70}$ y D. Catchpole ${ }^{71}$ D. Allison ${ }^{72}$, K. Berger ${ }^{73}$ y P. Sacchi ${ }^{74}$ afirman que sujetos humanos como Moisés, Juan el Bautista, o Jesús tendrían su doble celeste. Para nuestro interés, C. Fletcher Louis ${ }^{75}$ y K. Berger ${ }^{76}$ lo mencionan respecto del Hijo del Hombre marcano.

Sujetos como Enoch, Elías y Isaías son enviados con funciones escatológicas para socorrer al pueblo de Dios (Mc 1,2 y 9,11) o son vistos como arquetipos de los justos; es el caso de Enoch o José, en Sb 2,18; 5,5 y en Ap.Sof 9,4: “...todos los justos, vale decir Abraham, Isaac, Jacob, Enoch, Elías y David y hablan con él como un amigo habla con un amigo". Ciertamente, algunos textos del Evangelio -como Mc 1,2; 9, 3-4.12; 13, 13,6-remiten a este dualismo cósmico, creído y practicado por corrientes del judaísmo del segundo Templo, que explicaría la creencia en una vida gloriosa de patriarcas y profetas, algunos de los cuales son enviados por Dios.

\footnotetext{
${ }^{66}$ Vanderkam, "Richteous One, Messiah, Chosen one, and the Son of Man in 1Enoch 37-71", 183-184.

${ }^{67}$ Fletcher-Louis, Jesus Monotheism. Vol. 1: Christological Origins: The Emerging Consensus and Beyond, 103-104.

${ }^{68}$ Orlov, "Moses' Heavenly Counterpart in the Book of Jubilees and the Exagoge of Ezekiel the Tragedian", 153-173.

${ }^{69}$ Elior, The Three Temples: On the Emergence of Jewish Mysticism, 33.

${ }^{70}$ Koch, "Questions Regarding the So-called Son of Man in the Parables of Enoch: A Response to Sabino Chiala and Helge Kvanvig", 236-237.

${ }^{71}$ Catchpole, "The Angelic Son of Man in Luke 12:8”, 255-65.

${ }^{72}$ Allison, Constructing Jesus: Memory, Imagination, and History, 300.

${ }^{73}$ Berger, Theologiegeschichte des Urchristentums, 66-67.

${ }^{74}$ Sacchi, La historia del judaismo en la época del segundo Templo, 422.

${ }^{75}$ Fletcher-Louis, Fletcher-Louis, Jesus Monotheism. Vol. 1: Christological Origins: The Emerging Consensus and Beyond, 103.112.

${ }^{76}$ Berger, Theologiegeschichte des Urchristentums, 67.
} 


\section{La expresión $̋ ̋ \phi \theta \eta$}

La expresión $̋ ̋ \phi \theta \eta$ + dativo aparece en la LXX referida (1) a Dios (Gn 18,1): $\omega ̋ \phi \theta \eta \delta^{\prime} \epsilon$

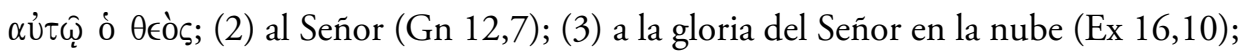
(4) al ángel del Señor, que se hace ver (Ex 3,2; Tb 12,22; Lc 1,11; 22,43; Hch 7,30;

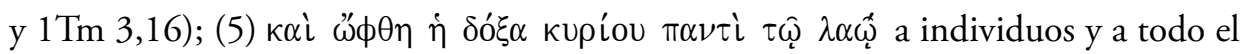

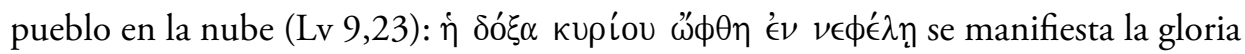
en la nube ( $\mathrm{Nm} 14,10 ; 20,6)$; (6) la expresión se manifiesta en sueños a reyes, profetas, apóstoles (1R 3,5; 2Cro 7,12; Dn [TH] 8,1), a veces, con el verbo фó $\iota \nu \omega$ (Mt 1,20; Hch 16,9; Ap 12,1).

Este uso no pareciera significar un grado menor de realidad que las expresiones donde la frase se relaciona con sujetos históricos específicos, como en las que se revela a reyes, patriarcas o apóstoles: por ejemplo, 1Co 15,5-8; Hch 13,31; 16,9; y al mismo Jesús (Mc 9,4; Lc 22,43).

El sumario expuesto muestra que se trata de una fórmula técnica común en la LXX para designar una teofanía o angelofanía y, por tanto, que Dios o seres celestes toman la iniciativa para dar a conocer su voluntad por diversos medios: visiones nocturnas, experiencias sensoriales directas individuales como colectivas ${ }^{77}$.

En relación con Marcos, Kremer señala que "el verbo ha de interpretarse a la luz de textos proféticos o apocalípticos del Antiguo Testamento y del judaísmo [...] con ocasión del bautismo (Mc 1,10) y con la aparición $(ڤ \phi \theta \eta)$ y la visión durante la transfiguración (Mc 9,4-9)”78. Además, subraya que no posee el sentido técnico exclusivo para las apariciones del Resucitado; es decir, $̋ ̋ \theta \eta$ introduce una interpretación dualista de una revelación actual a reyes, profetas, o apóstoles. La aparición despliega una visión de la realidad en la que conviven dos planos, uno celeste y otro terrenal.

Por el contrario, R. Pesch sostiene en esta línea que se trata de una fórmula de legitimación de profetas y apóstoles ${ }^{79}$, es decir, posterior a la experiencia misma. En su opinión, dicha fórmula posee una función legitimadora del mensaje del apóstol o profeta, por lo cual el núcleo de la fórmula no radica en el medio empleado por Dios para comunicar el encargo, ya sea como visión nocturna, experiencia extática, particular o grupal.

W. Michaelis discute sobre el carácter objetivo o subjetivo del suceso, al señalar que "la transfiguración de Jesús, Mc 9,2, no es considerada como una experiencia

\footnotetext{
${ }^{77}$ Kremer, "ovra,w”, 586.

${ }^{78}$ Ibíd., 585.

${ }^{79}$ Vögtle y Pesch, Wie kam es zum Osterglauben, 156.
} 
extática de Jesús mismo...”80 entendiendo éxtasis como una experiencia incorpórea; y para ello distingue entre apariciones y sueños.

Sin embargo, Kremer considera que la expresión no es una mera fórmula de legitimación sino que remite a una experiencia real: “ $ڤ \phi \theta \eta$ no se usa con este fin ni en los profetas ni en ninguna otra parte del Nuevo Testamento" ${ }^{81}$. Lo mismo señala Ch. Rowland, quien sostiene que la transfiguración fue un tipo de experiencia: "ellos han visto a Jesús en la forma de un enviado como ángel" ${ }^{82}$, similar a la vivida por Pablo, el vidente del Apocalipsis u otros más. Respecto del primer punto, hay que decir que la cosmovisión dualista presente en estos textos judíos no discrimina acerca del carácter subjetivo u objetivo de visiones, éxtasis, o apariciones; todas ellas poseen la connotación de experiencias sensoriales (2Co 12,2-4).

\section{Profeta escatológico e Hijo del Hombre}

El uso de diversos textos veterotestamentarios empleados en los evangelios (Ml 3,24, Dt 18,15-19; Is 61,1-2) representa un punto de partida obligado en la cuestión que nos ocupa. Como ha sido subrayado por diversos autores, el empleo de estos textos no es azaroso y responde a razones que se hunden en la historia de la primera predicación cristiana. Si se toma en cuenta que el título de profeta resultó ineficaz en el tiempo pospascual, resulta absurdo enmarcar la predicación de Jesús de Nazaret como un profeta, a no ser que responda a un recuerdo histórico originario.

No sin razón, autores como J. Hayes ${ }^{83}$, J. Robinson ${ }^{84}, \mathrm{~K}_{\text {. Berger }}{ }^{85}$, R. Pesch ${ }^{86}$, J. Dunn ${ }^{87}$, O. Walker ${ }^{88}$, J. Heil ${ }^{89}$ sostienen que una de las primeras formulas cristológicas tuvo como base la expectativa mesiánica del profeta escatológico. Ahora bien, a diferencia de los profetas milenaristas descritos por F. Josefo, en otros grupos

\footnotetext{
${ }^{80}$ Michaelis, “ovra,w”, 354.

${ }^{81}$ Kremer, "ovra,w”, 586.

${ }^{82}$ Rowland, The Open Heaven: A Study of Apocalyptic in Judaism, and Early Christianity, 368.

${ }^{83}$ Hayes, "The Resurrection as Enthronement and the Earliest Church Christology", 333-345.

${ }^{84}$ Robinson, “The Most Primitive Christology of All?”, 187.

${ }^{85}$ Berger, Theologiegeschichte des Urchristentums, 66.

${ }^{86}$ Pesch, "Zur entstehung des Glaubens an die Auferstehungen Jesu. Ein Vorschlag zur Diskussion", 201-228; Pesch, "La genese de la foi en la resurrection de Jésus", 51-74.

${ }^{87}$ Dunn, "Messianic Ideas and Their Influence on the Jesus of History", 377.

${ }^{88}$ Walker Jr., "Christian Origins and Resurrection Faith", 54.

${ }^{89}$ Heil, The Transfguration of Jesus: Narrative Meaning and Function of Mark 9:2-8, Matt 17:1-8 and Luke 9:28-36, 92.
} 
sectarios dicha expectativa mesiánica del profeta escatológico fue entendida de manera angelomórfica (Melquisedec, Elías, Moisés).

Es importante notar que esta expectativa mesiánica posee una connotación importante para nuestro objetivo, pues se trata de textos ciertamente judíos que proponen una comprensión dualista profético-mesiánica trascendente; es decir, el profeta o mesías es considerado como perteneciente a la esfera divina, al realizar funciones aplicadas a Yahveh, pero distinto a él. Melquisedec o Elías no son una hipóstasis divina, sino ángeles que comparten funciones judiciales, taumatúrgicas o doctrinales atribuidas a Yahveh. Mencionemos a continuación los casos de Melquisedec, Elías y Moisés.

En primer lugar, el testimonio de 11QMelq muestra la figura de Melquisedec como profeta escatológico angelomórfico ${ }^{90}$. Esto lo podemos apreciar en el texto, en cuyo v. 6 menciona la figura del ángel Melquisedec (véase Gn 14,18; Sal 110,4) en relación con el texto de Is 61. El pesher interpreta el pasaje de Dt 15, 1-2 ("Cada siete años harás remisión”) interpretado de manera escatológica a partir de Is 61,1 . El pesher vincula la figura de Melquisedec con el profeta escatológico de Is 61,1-2 en cuatro oportunidades (vv. 6, 9, 13 y 20). En las tres primeras Melquisedec es explícitamente mencionado. De acuerdo con lo planteado por D. Kirk, Melquisedec cumple "funciones" aplicadas a Yahveh, como la de realizar el juicio en el décimo jubileo. Esto muestra que la identidad celeste de Melquisedec fue comprendida desde la perspectiva de las funciones escatológicas que eran exclusivas de Yahveh.

En segundo lugar, en otro texto (4Q521) muestra el arribo del eschaton por medio del envio de un mesías profético semejante a Elías. El texto de 4Q521,1 -"los cielos y la tierra escucharán a su mesías (למשיהו)"-, que remite a Sal 146 referido a la persona de Yahveh; en cambio, en el relato de 4Q521, la expresión ha sido referida al rol del mesías, no a Dios; es decir, las funciones divinas que mencionaba el salmo han sido traspasadas a las funciones del mesías profético.

En otro texto, 4Q377, aparece un Moisés mesiánico-angelomórfico (4Q377 fr. 1 recto col. II, 5-12); específicamente en el v. 5, Moisés es designado como "su mesías" (מושה משיחו), y en el v. 10, como "el hombre de Dios" (מלואן) (מיש האלוהים), "ángel" (מלאך) y "evangelizador" (מבשר). En este último texto no encontramos un traspaso de funciones; es decir, no presenta roles salvificos, pero el término evangelizador ofrece más bien aspectos místicos del profeta mosaico en su relación con con Yahveh.

\footnotetext{
${ }^{90}$ Carbullanca, "Orígenes de la cristología del cuarto Evangelio. Un estudio a partir de la tradición de 11QMelquisedec”, 517-547; Carbulanca, Cristología del Evangelio de Marcos, 339ss.
} 
Ahora bien, también encontramos la expectativa del profeta escatológico aplicado al líder, quizás -como afirma D. Kirk- una figura idealizada de profeta escatológico, a quien Dios entrega su espíritu (col. XX, 12; col. IV, 26; 4Q427 fr.2,12)². En el relato de 1QHa, col. XXIII, fr. 1, y en 11QMelq, v. 20, el Maestro de justicia se aplica a sí mismo el relato de Is 61,1: “...un heraldo (מבשר) de tu bondad, para proclamar a los pobres la abundancia de tu compasión [...] de una fuente [...] a los de espíritu quebrantado, y a los que están de duelo eterna alegría”.

Por ello, es probable que este texto haya sido actualizado también por el mismo Jesús, como bien lo señala J. Dunn ${ }^{92}$. Con estos antecedentes de una mesianología alta no resulta extraño preguntarse si el relato de la transfiguración -al mencionar las figuras de Elías y Moisés, "Y les apareció Elías con Moisés, que hablaban con Jesús" (v. 4) - se inscribe en una práctica ya existente en corrientes judías del siglo I, en Palestina.

En relación con la figura del Hijo del Hombre, en el relato de la transfiguración de Mc 9,9 ("descendiendo ellos del monte, les mandó que a nadie dijesen lo que habían visto, sino cuando el Hijo del hombre hubiese resucitado de los muertos") es claro que, en tradiciones judías, figuras como Enoch y el Hijo del Hombre realizan funciones escatológicas propias de su autoridad angelomorfica ${ }^{93}$ como atar a Azazel, interceder por los justos, realizar el juicio escatológico e iniciar los nuevos cielos y la nueva tierra.

En la discusión sobre estas figuras resulta curioso que L. Hurtado no considera que la figura del Hijo del Hombre de las Parábolas describa al Hijo del Hombre como significativo, o haya influenciado al Jesús de los evangelios; más bien ofrece una interpretación sociolingüística de la expresión Hijo del Hombre, ò viòs tô̂ $\dot{\alpha} \nu \theta \rho \omega^{\prime} \pi \mathrm{v}^{94}$, que no guarda relación alguna con el Hijo del Hombre apocalíptico; esta

\footnotetext{
${ }^{91}$ La terminología empleada por los diversos autores es problemática: por un lado, R. Bauckham habla de una "divine identity Christology"; L. Hurtado habla de un bi-teismo; y D. Kirk prefiere hablar de "idealized human figures" para proponer una alta, humana cristología. Estas terminologías tienen serias complicaciones pues el judaismo del siglo I no conoció de una identidad sicológica o metafísica, sino que el concepto de identidad semítico es mítico-funcional y no psicológico. Como ha sido estudiado, la construcción de la identidad es producto de la cultura de cada época, lo cual significa asumir en los estudios neotestamentarios que el yo literario de los relatos estudiados no es un yo psicológico o metafísico sino un yo mitico-funcional.
}

${ }^{92}$ Dunn, "Messianic Ideas and Their Influence on the Jesus of History”, 377.

${ }^{93}$ Carbullanca, "Cristología del Evangelio de Marcos", 341ss.

${ }^{94}$ Hurtado, Señor Jesucristo. La devoción a Jesús en el cristianismo primitivo, 352. 
posición se aprecia en su consideración de textos -por ejemplo, Mc 14,62-64-como un mero recurso literario ${ }^{95}$.

Por el contrario, paradójicamente, R. Bauckham sostiene que la única figura intermedia en compartir la soberanía de Yahveh es el Hijo del Hombre de las "Parábolas de Enoch" ${ }^{96}$, al señalar: "I do not think they are likely to have influenced Christology" ${ }^{97}$, aunque es evidente que el libro "Parábolas de Enoch" asume el relato de Dn 7,11-13 acerca del Hijo del Hombre y que Dn 7,11-13 ha influenciado textos neotestamentarios.

Autores como U. Wilckens ${ }^{98}$, Fletcher-Louis ${ }^{99}$, R. Pesch ${ }^{100}$ establecen diversas conexiones entre Enoch y el Hijo del Hombre marcano, entre las cuales sobresale, primero, la comparación entre los motivos de Adán y del Hijo el Hombre; y segundo, la escatología de las "Parábolas de Enoch" y Marcos.

En relación con lo primero, diversos relatos marcanos remiten al paradigma de Adán (véase $1,13.24 .40-45 ; 2,6-7.28 ; 5,8 ; 14,64$ ) ${ }^{101}$. En esta perspectiva, J. Parkman hace una comparación entre Adán y el Hijo del Hombre, para señalar: “...it would be easy enough to understand the one Daniel sees in his vision as a 'son of Adam'" ${ }^{102}$; también D. Kirk reconoce el trabajo de J. Marcus y relaciona al Hijo del Hombre marcano con Adán, mediado por el texto de Dn 7,11-13 $3^{103}$.

En relación con la escatología, estas comparaciones entre el texto de Dn 7 , 11-13, 1Enoch 70-71 y el Hijo del Hombre marcano son importantes, pues ayudan a diferenciar entre exaltación y resurrección. El Hijo del Hombre de las "Parábolas

95 Ibíd., 343.

${ }_{96}$ Bauckham, God Crucified. Monotheism and Christology in the New Testament, 19.

${ }_{97}$ Bauckham, Jesus and God of Israel. God Crucified and Other Studies on the New Testament's Christology of Divine Identity, 150.

98 Wilkens, Resurrection, 102-104.

99 Fletcher-Louis, Jesus Monotheism. Vol. 1: Christological Origins: The Emerging Consensus and Beyond, 65ss.

${ }^{100}$ Pesch, Das Markusevangelium II, 74.

${ }^{101}$ Naizer, "Adam, Humanity, and Angels: Early Jewish Conceptions of the Elect and Humankind Based on Genesis 1-3", 12. Señala el autor en relación con texto de Qumrán 4QInstruction: "In each of the two creation narratives in Genesis 1-3, humanity is portrayed differently. Second Temple Jewish authors would regularly turn to the Adam of Gen 1, 26-27 to assert a "high" anthropology_associated with the heavenly realm, while the Adam of Gen 2:7 was consistently read as portraying a "low" anthropology" (cf. Kirk, "Daniel. Mark's Son of Man and Paul's Second of Adam", 181-182). El relato de Mc 1,13, así como los relatos de autoridad del Hijo del Hombre siguen el modelo de una antropología alta que muestra a Jesús en imagen de Dios, según Gn 1,26.

${ }^{102}$ Parkman, "Adam Christological Motifs in the Synoptic Traditions", 29.

${ }^{103}$ Kirk, "Daniel. Mark's Son of Man and Paul's Second of Adam”, 179. 
de Enoch" no resucita sino es transformado y entronizado, y con él son declarados la nueva creación y el juicio final (1Enoch 70-71), como lo entenderá Mc 14,62: "Y Jesús le dijo: Yo soy; y veréis al Hijo del Hombre sentado a la diestra de la potencia de Dios, y viniendo en las nubes del cielo".

Esta diferencia explica aspectos de la escatología marcana como la sospecha de blasfemia que significó esta apropiación de Dn 7,9 para el judaísmo rabínico ${ }^{104}$. Nosotros creemos que el Evangelio y el relato de la transfiguración revelan una cristología alta desarrollada mediante un dualismo espacial caracterizada por diversas referencias a Jesús como el Hijo, sumo sacerdote y nuevo Adán.

$$
\mu \epsilon \tau \epsilon \mu о \rho \phi \omega^{\prime} \theta \eta
$$

Respecto del término $\mu \in \tau \in \mu о \rho \phi \omega ́ \theta \eta$ es importante señalar que $ڤ ̋ \phi \theta \eta$ significa "se dejó ver", mientras que $\mu \in \tau \in \mu о \rho \phi \omega ́ \theta \eta$ significa "fue transformado" o "se transformó" en el contexto de narrativas místico-milenaristas, e implica una transformación permanente, como se puede acreditar por otros textos similares, en los cuales se habla tanto de una transformación inmanente de la creación como de una transformación del cuerpo terreno en otro de luz o glorioso; así, por ejemplo, en 2Esd 2,39.45; 1Enoch 71,1, "vestidos de gloria"; lo mismo encontramos en textos como 1Enoch 39,4-5; 62,15; 108,11; 2 Enoch 9,20; y Ap.Sof 8,3.

Dicha terminología es importante en vista de enmarcar la comprensión que tuvo el cristianismo marcano del eschaton, es decir, la transformación del cuerpo predicado de Jesús en la montaña se relaciona con trayectorias místico-milenaristas que hablaban de dicha transformación: "se convertirán en ángeles en el cielo, sus rostros brillaran de júbilo"(1Enoch 51,5); también "los justos [...] llevando vestiduras de gloria"(1Enoch 62,15); "vi los hijos de los santos ángeles andando sobre llamas de fuego, sus vestidos y túnicas eran blancas y sus rostros resplandecientes como granizo” (1Enoch 71,1) "y transfiguraré a los que nacieron en tinieblas" (1Enoch 108,11).

Un primer elemento de esta trayectoria radica en la expresión $\mu \in \tau \epsilon \mu о \rho \phi \omega \dot{\theta} \eta$, en

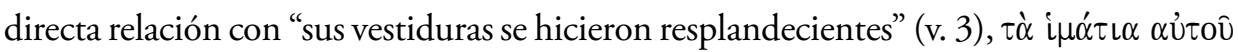

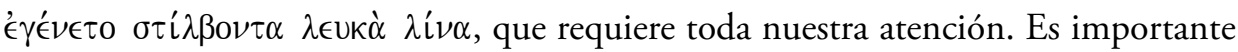
notar el contraste con los paralelos que posee el relato acerca de la transfiguración de Moisés (Ex 24,16; 34,29-35; 2Co 3,7-18), y a diferencia de Moisés -quien se pone un "velo" para descender-, Jesús aparece a continuación solo en su humanidad. Nótese que la transformación del rostro de Moisés no es momentánea sino permanente; por

${ }^{104}$ Segal, Two Powers in Heaven: Early Rabbinic Reports about Christianity and Gnosticism, 95. 
esto debe colocarse un velo ${ }^{105}$. Sin embargo es importante atender la diferencia con los evangelios de Lucas y Mateo en relación con el resplandor.

Mt 17,2, "su cara resplandeció como el sol", que reproduce a Ex 34,35, "su cara resplandecía”, y en la LXX, Ex 34,35 señala que "el rostro de Moisés fue glorificado",

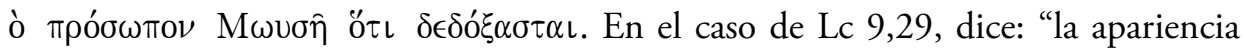

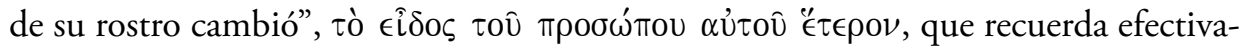
mente el rostro transfigurado de Moisés.

En cambio, la versión de Mc 9,3, "sus vestiduras se hicieron resplandecientes,

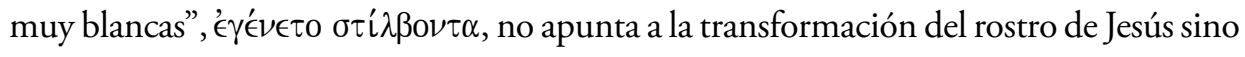
al motivo de la transformación de las vestimentas, lo que es recurrente en movimientos milenaristas e indica una transformación permanente de visionarios como Enoch, Levi, Isaías, Metatron, etc., que presupone el ascenso al cielo, como señala R. Pesch ${ }^{106}$ (4Esdras 2,39; 1 Enoch 62,15; 2Enoch 22,8-10; Ap 3,5; 6,11; 7,913-14; 19,14).

Los relatos que hablan de una transformación por medio de la entrega de vestiduras refulgentes, coronas o la entronización responden al motivo del cuerpo, de carne/cuerpo celeste (AscIs 4,17;9,9; 11,35). La mayor gloria de unos ángeles respecto de otros está marcada por la luz y por el conocimiento de los misterios, lo que muestra el carácter jerárquico de tales seres ${ }^{107}$.

Como veremos, la ignorancia que expresa la respuesta de Pedro (v. 5) no es casual y refleja que Pedro no acierta a dar a Jesús un estatus superior al de Elías y Moisés; el narrador señala: "no sabía lo que hablaba, porque estaban espantados" (v. 6). Por el contrario, la voz divina en Mc 9,7 revela la identidad de Jesús. En un estilo pesher (Mc 9,13; Lc 7,27), la voz declara la identidad celeste de Jesús, el Hijo del Hombre, que es superior a la de las otras dos figuras celestes ${ }^{108}$.

Un segundo elemento está representado por la expresión de Mc 9,3, "sus

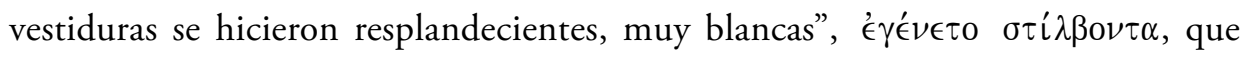
mostraría -en opinión de Ch. Talbert ${ }^{109}$ y J. Dunn ${ }^{110}$ - una vinculación con cristologías basadas en la tipología Adán/Cristo. Ch. Talbert sostiene, en efecto, que el "primitivo

${ }^{105}$ Heil, The Transfiguration of Jesus: Narrative Meaning and Function of Mark 9:2-8, Matt 17:1-8 and Luke 9:28-36, 90-92.

${ }^{106}$ Pesch, Das Markusevangelium II, 75.

${ }^{107}$ Boccaccini, I Giudaismi del Secondo Tempio. Da Ezejiele a Daniele, 91-93.

${ }^{108}$ Sullivan, Wrestling with Angels. A Study of the Relationship between Angels and Humans in Ancient Jewish Literature and the New Testament, 114.

${ }^{109}$ Talbert, "The Problem of Pre-Existence in Philippians 2:6-11”, 151.

${ }^{110}$ Dunn, Christology in the Making. A New Testament Inquiry into the Origins of the Doctrine of the Incarnation, 107. 
cristianismo conoció tradiciones, las cuales consideraron a Jesús como un segundo Adán [...] y tradiciones que consideraron a Jesús como hijo de Adán (Lc 3,23)" ${ }_{111}$, según los textos de Rm 5,12ss., Mc 1,13 y Lc 4,1ss.

James Dunn sostiene con fundamento, a nuestro parecer, que existieron tradiciones prepaulinas (Fil 2,6-9) portadoras de una cristología adámica ${ }^{112}$ (Col 1, 15-20) en la cual la semejanza de Adán-Cristo se logra en la resurrección. En la misma perspectiva Fletcher-Louis sostiene que, en tradiciones judías, el sumo sacerdote es un nuevo Adán, "usando las vestimentas perdidas por Adán en el paraíso" ${ }^{113}$ a partir de lo cual Marcos 1-6 discute nada menos que la existencia de un Hijo del Hombre sacerdotal ${ }^{114}$.

Autores como Nicholas Perrin han estudiado la cuestión de Jesús como sumo sacerdote en Marcos ${ }^{115}$, sin revisar el relato de la transfiguración. No es casual entonces que autores como J. Marcus señalen que la transformación de la vestimenta de Jesús, en Mc 9,4, se asemeja no a la tipología mosaica sino a la tipología de Adán ${ }^{116}$. Marcus establece la relación de dos comparaciones: las vestimentas de Jesús y la del sumo sacerdote, y la montaña de la transfiguración, y la del Edén ${ }^{117}$, para concluir que "en la transfiguración [...] muestra una visión de la gloria adámica de Jesús" ${ }^{118}$.

La observaciones de Nicholas Perrin y de Joel Marcus no son peregrinas, si se toman en cuenta los relatos en los cuales se indican funciones sacerdotales y otros referidos a la convivencia de Jesús con los ángeles, los animales y la expulsión de demonios (véase 1,13.24.40-45; 2,6-7.28; 5,8;14,64). Es importante notar, aunque sea de paso, que el relato programatico de Mc 1,13 muestra la figura de Jesús como

\footnotetext{
${ }^{111}$ Talbert, "The Problem of Pre-Existence in Philippians 2:6-11", 151.

${ }^{112}$ Dunn, Christology in the Making. A New Testament Inquiry into the Origins of the Doctrine of the Incarnation, 114-121.
}

${ }^{113}$ Fletcher-Louis, "Jesus as the High Priestly Messiah: Part 1", 160. Como es el caso de TLevi 17,1: "ya habéis oído lo de las setenta semanas, escuchad ahora lo del sacerdocio: en cada jubileo habrá un sacerdocio [...] en la quinta semana volverán a su tierra desolada, y reedificaran la casa del Señor, en el séptimo [...] habrá paz en todo el mundo, [...] los cielos se abrirán él abrirá las puertas del paraíso y apartará de Adán la espada amenazante [...] él atará a Belial”. En el fragmento, 4Q213b 4QAramaic Levi c, el patriarca, luego de un sueño, recibe una visión, en el v. 6, donde se menciona que Leví es constituido como mesías sacerdote-eterno de la misma manera que es Melquisedec: "Yo he llegado a ser sacerdote eterno para Dios".

${ }^{114}$ Fletcher-Louis, “Jesus as the High Priestly Messiah: Part 1”, 178.

${ }^{115}$ Perrin, "Jesus as Priest in the Gospels", 83.

${ }^{116}$ Marcus, Mark 1-8. A New Translation with Introduction and Commentary, 636; Steenburg, "The Worship of Adam and Christ as Imagen of God", 479-505.

${ }^{117}$ Marcus, Mark 1-8. A New Translation with Introduction and Commentary, 638.

${ }^{118}$ Ibíd., 640. 
nuevo Adán que abre el Paraíso. El Jesús marcano que dialoga con demonios y es interlocutor de los animales realiza, como Hijo del Hombre, funciones sacerdotales como son el perdón de los pecados (Mc 2,6-7), la sanación de enfermos (Mc 1,40-45) y la realización del juicio $($ Mc 14,64).

\section{"Este es mi hijo amado"}

La designación de hijo muestra aspectos de continuidad y ruptura con tradiciones judías que muestran antecedentes para las primeras cristologías apocalípticas sobre el Hijo. En diversos textos judíos (José y Asenet 6,2-6; Sb 2,18;5,5; 1Enoch 104, 3; 4Q372 fr.1 v. 1) se expresa que los justos son llamados hijos de Dios. Así, en el relato de "José y Asenet", en "José, el hijo de Dios" $(6,2.6)$ y en el Libro de la Sabiduría se afirma que justos como José -o como Enoch-son transformados de justos en hijos de Dios (vv. 2,18; 5,5), y que los justos llaman a Dios su Padre, en medio de sus sufrimientos (Sb 2,16.18).

De la misma manera, en textos apocalipticos -como 1Enoch 104, 3; 105,32; 4Esd 7,27-28;13, 13.32-, el Hijo del Hombre o el Mesías es denominado "mi Hijo" y, en 2Enoch 23,52, Melquisedec es llamado "mi niño", en sentido relativo para hablar de los justos (Sb 2,16.18; T. Benjamin 3,7; “Apócrifo de José”, 4Q372 fr.1 v.16). En este último texto, el "Apócrifo de José" (4Q372), José abandonado por sus hermanos, y clama a Dios: "Mi Padre y mi Dios no me abandones en manos de los gentiles [...] hazme justicia para que el pobre y afligido no perezca".

Estos datos muestran que la denominacion de hijo, no en términos absolutos, fue empleada en círculos judíos que se consideraban a sí mismos como justos, perseguidos y maltratados, que invocaban a Dios como su Padre ("José y Asenet”, 6,2.6; Sb 2,16.18;4Q372) o que compartían la creeencia de que el mesias recibiría la denominación de Hijo en términos absolutos, como en Mt 11,27//Lc10,22. Aplicado a Jesús encontramos que sigue dos modelos: primero, connotaciones mesianicas por causa de su resurrección (1Ts 1,10; Rm 1,4; Hch 3,33; Hb 1,5; Mc 8,38; 13,32; Lc 10,20$)^{119}$, es decir, el ingreso de un sujeto humano en la esfera divina lo constituye en Hijo y Mesias.

En el segundo modelo, autores como Öhler y Loader desarrollan la tesis de la filiación apocaliptica ${ }^{120}$ de profetas, mártires y mesías. Loader refiere el relato de la transfiguración: "Es difícil no ver una original referencia a una apocalíptica filiación

119 Öhler, "Die Verklarung (Mk 9,1-8): Die Ankunft der Herrschaft gotters auf der erde”, 213.

${ }^{120}$ Ibíd., 214-215; Loader, "The Apocalyptic Model of Sonship: Its Origin and Development in New Testament Tradition”, 528. 
de Jesús" ${ }^{121}$. M. Casey lo considera un título cristológico de exaltación empleado por la Iglesia primitiva ${ }^{122}$. Wilcken señala, por ejemplo, que 1Enoch 71,14, "tú eres el Hijo de Hombre que has nacido en justicia”, que aparece en Sal 2,7, era empleado por la primitiva Iglesia (Hch 13,33; Hb 1,5;5,5) como un nacimiento celeste del Hijo del Hombre. No es menor señalar que, en apoyo de esta posición, el nuevo nacimiento es proclamado en el bautismo y la transfiguración, aplicando el Sal 2,7, tanto en Mc 1,11 como en Mc 9,7123.

En segundo lugar, en continuidad con tradiciones judías, se predica la filiación actual de justos como José, Enoch o los profetas; así lo encontramos en los textos de Mc 1,11; 9,7; 12,6 y14,36. En el último de estos, el "Abba, Padre", así como el "Apócrifo de José" (4Q372), se muestra que la filiación de Jesús y de José es actual y no necesita esperar la resurrección para invocar a Dios como su Padre, sino que siguen el tenor de diversos textos judíos sobre los justos perseguidos.

En el relato de la transfiguración, la voz que surge de la nube declara sobre

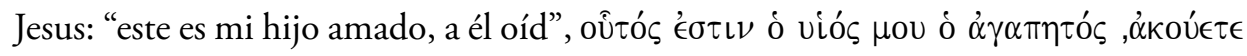

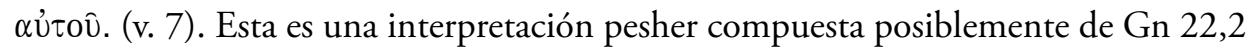
y Dt 18,15 , que no solo pretende identificar epistemológicamente al sujeto que ha sido transformado, sino realizar una interpretación escatológica de la identidad de Jesus; por tanto adquiere un sentido pragmático. La expresión pretende expresar que ya, ahora, Jesus de Nazaret es el Hijo amado (Mc 1,11; 12,6;15.39). En los tres sitios en los cuales se aplica el término a Jesús de Nazaret tiene un sentido de realizar una función escatológica de revelación de los misterios. El Hijo tiene la autoridad profético escatológica ${ }^{124}$ en su humanidad, como la más alta revelación cristológica.

Esta filiación que muestra el relato de la transfiguración -como se ha anotadono es el único en el Evangelio. En el dicho de Mc 8,38 que ha sido considerado auténtico por la crítica se establece una vinculación entre las cristologías de Hijo del Hombre y del Hijo. Este dicho menciona la venida del Hijo del Hombre en la gloria del Padre, en compañía de sus ángeles. Si se acepta la autenticidad, se debe estar de acuerdo también con que Jesús de Nazaret o los primeros cristianos utilizaron el imaginario de la entronización en la gloria, rodeada de ángeles, para referirse a su inminente estatus a la derecha del Padre, en las nubes del cielo.

${ }^{121}$ Ibíd., 540.

${ }^{122}$ Casey, Casey, From Jewish Prophet to Gentile God, 44.

${ }^{123}$ Wilkens, Resurrection, 103.

${ }^{124}$ Carbullanca, "Muerte de Cristo en el Evangelio de Marcos. Estudio de varias tradiciones del martirio", 468. 
Ahora bien, el dicho de Mc 8,38 afirma una filiación futura del Hijo del Hombre al sostener que "el Hijo del Hombre vendrá en la gloria de su Padre". El modelo de filiación divina postula un estatus futuro del Hijo del Hombre, y por tanto es un modelo de transformación. Loader comprueba este mismo modelo de filiación en los pasajes de Mc 8,38 y 13, 32. En el primero (Mc 8,38), la filiación del Hijo del Hombre está relacionada con la denominación "mi Padre", y Loader nota la continuidad entre ambas designaciones, puntualizando que el título Hijo del Hombre se refiere fundamentalmente a la función escatológica, mientras que Hijo se refiere a la relación actual del Hijo en relación con el Padre ${ }^{125}$.

La convivencia en el Evangelio de Marcos de ambas perspectivas de filiación presente-futuro representa una cristología alta que hunde sus raíces en la propia experiencia de Jesús de Nazaret, y no solo en la reflexión que realizó la comunidad a partir de su resurrección. Más todavía, esta autocomprensión actual que se retrotrae al mismo Jesús habría sido el elemento más escandaloso de su predicación, en vista del monoteísmo judío. Ciertamente, la transformación angelomórfica del Justo, y más específicamente del Hijo, ayudó a la formulación del origen divino del Mesías, en un sentido radicalmente superior al que postulaban los círculos apocalípticos. Es factible pensar que, en continuidad con creencias de la filiación de los justos y las expectativas judías sobre la filiación del mesías, el cristianismo primitivo continuó y reelaboró la realización plena de su filiación con su plena entronización como Señor (Rm 1,3ss.; Flp 2,11).

\section{Autoridad y conocimiento}

La cuestión de la ignorancia ante la transformación de Jesús queda evidente en la respuesta de Pedro (v. 5). Al respecto, K. Sullivan ${ }^{126}$ hace una comparación interesante entre el logion 13 del Evangelio de Tomas y el relato de la transfiguración, según la cual en ambos textos la intervención de Pedro es inadecuada. La declaración de Pedro, “eres como un ángel”, es incorrecta: Jesús es más que un ángel; en cambio, Tomás afirma: "Mi boca no es capaz de decir a quién te parecer tú". El narrador señala: "No sabía lo que hablaba; pues estaban espantados" (v. 6).

El contraste es notorio y deliberado. La única voz autorizada proviene de la segunda escena del relato, en Mc 9,7, "vino una nube haciéndoles sombra, y desde

${ }^{125}$ Loader, "The Apocalyptic Model of Sonship: Its Origin and Development in New Testament Tradition", 531.

${ }^{126}$ Sullivan, Wrestling with Angels. A Study of the Relationship between Angels and Humans in Ancient Jewish Literature and the New Testament, 116-117. 


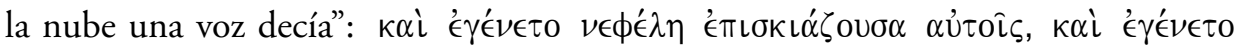

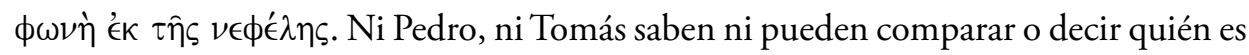
Jesús. La voz divina es la única que sabe la diferencia e identidad de Jesús. En un estilo pesher (Mc 9,13; Lc 7,27), la voz declara la autoridad (exousia) escatológica de Jesús

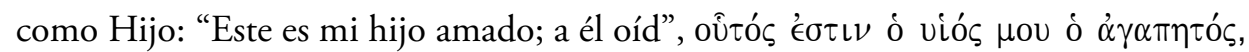

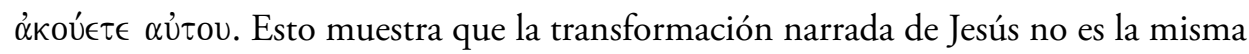
que la de las otras dos figuras celestes: en este sentido, el relato destaca que la autoridad de Jesús supera a la autoridad angelomórfica de Elías y Moisés ${ }^{127}$.

Autoridad y conocimiento son entendidos en términos estratificados, lo que es evidente en el logion de Mc 13,32, "de aquel día y de la hora, nadie sabe; ni aun los ángeles que están en el cielo, ni el hijo sino el padre” (Lc 10,22; Ef 1,21; Col 2,10: 1Q27 fr.1 col. I,2; 4Q492 fr.4 14). Este dicho se hace parte de la visión en la cual la realidad está estratificada de acuerdo con la autoridad y conocimiento de los misterios de Dios; ni los ángeles, ni el Hijo conocen los misterios de Dios. En cambio, en Lc 10,22, el Hijo conoce los misterios, y luego los ángeles y justos, los demonios, los hombres. Así las cosas, la revelación de los misterios es una función escatológica que depende de la autoridad que cada sujeto posea, por lo que la revelación del Hijo es prerrogativa del Padre, así como la hora del juicio.

\section{Resurrección o venida del Hijo del Hombre}

Tradicionalmente, el relato de la transfiguración ha sido calificado como una aparición del Resucitado, la cual había sido trasladada de lugar.

En Marcos no faltan menciones de la resurrección en términos formales, en el contexto del judaísmo, en el cual existen creencias del retorno de figuras proféticas del pasado en otra forma, en el eschaton (Mc 9,11; 8,31; 9,31; 10,30). Además,

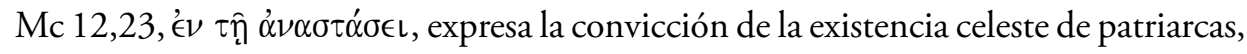
según la creencia de la transformación en ángeles ${ }^{128}$, lo mismo que Mc 12,25, "son

\footnotetext{
${ }^{127}$ Ibíd., 114; Carbullanca, "Muerte de Cristo en el Evangelio de Marcos. Estudio de varias tradiciones del martirio", 472.

${ }^{128}$ Tanto en el judaísmo oficial como en el mismo cristianismo se conoció una doctrina de "los dos poderes" (bHag 15a; Haggada del Pesaj 5,59; Col 2,18; Ap 19,10; 22,8) que percibió esta como una amenaza, ya al monoteísmo o a la soberanía de Dios (Tuschling, Angels and Orthodoy. A Study in their Development in Syria and Palestine from Qumran Texts to Ephrem the Syrian, 103). Desde la época macabea podemos comprobar que el fin de los justos estaba vinculado a la transformación del justo en estrella, así como los ángeles (Dn 12,2-3); y el judaísmo rabínico comprendió el problema que algunos ambiguos pasajes de la Escritura -como Ez 1,26 y Dn 2, 7, 11-13; 9, 26-, seg+im comenta Flavio Josefo, en Guerra judía 6,312-313 respecto de Dn 9,26 (Segal, Two Powers in Heaven: Early Rabbinic Reports about Christianity and Gnosticism, x).
} 


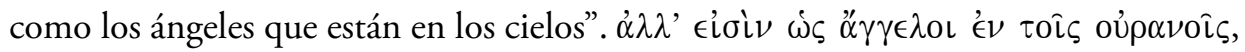
"cuando resuciten de entre los muertos", explica la expresión "cuando", ö $\tau \alpha \nu \delta \epsilon$

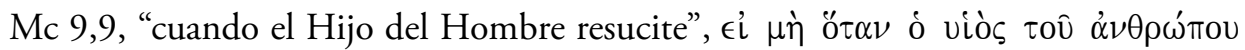
є́к $\nu \in \kappa \rho \omega \hat{\nu} \alpha \dot{\alpha} \nu \alpha \sigma \tau \eta$, referida a la resurrección, como muestra la escatología judía, e inscribe este "cuando", ö $\alpha \nu$, como una más de las señales en una secuencia de signos de la parusía (Mc 12,25 13,4.7.11.14.28.29; Lc 11,30; 1Co 15,23-28; 2Ts 1,10) pero aún sin contenido.

Esto explica el empleo general de los verbos '́ $\gamma \epsilon i ́ \rho \omega$ y $\alpha \nu \nu \iota \tau \eta \mu \iota$ referidos a diversos hechos: a Juan el Bautista (Mc 6,14.16), al retorno de otros profetas (Mc 6,15; 8,28; Lc 9,19), a enfermos $(5,42 ; 9,27)$, a Jesús (Mc 8,31; $9,10 ; 14,28 ; 16,6.9 .14)$. Por otra parte es importante advertir que diversos textos en el Evangelio de Marcos se refieren a la venida del Hijo del Hombre (Mc 9,1; 13,26; 14,64) y muestran un significado de resurrección monoteísta, diverso del sentido técnico y específico que encontramos en otros textos neotestamentarios, como 1Co 15,20 o Col 1,15-18. Como puede comprobarse, el evangelista comparte la creencia en la pronta irrupción del Reino de Dios (Mc 9,1), por lo cual cree que algunos estarán vivos para dicho evento. La expresión no "gustarán la muerte" se refiere al arrebato de los discípulos según el modelo de profetas y mártires como Moisés, Elías o Enoch y otros héroes legendarios como Esdras (4Esd 6,9) ${ }^{129}$.

Este texto de 4Esd 6,9, "porque tú serás arrebatado desde los hombres y estarás allí con mi Hijo y con los que son como tú hasta el tiempo sea terminado", muestra que la expectativa del arrebato al cielo es similar a la de otros textos del siglo I d. $\mathrm{C}^{130}$. El mismo marco ideológico explica que el relato de la transfiguración está dirigido a los cristianos $(9,1.9)$ que viven en este intervalo de tiempo entre la muerte y el regreso del Hijo del Hombre ${ }^{131}$, y que los discípulos son esos que "no gustarán la muerte hasta que vean ( $(\delta \omega \sigma \iota \nu)$ el Reino de Dios viniendo con poder".

Ello refleja que se equivoca quien centra la problemática del relato de la transfiguración en la resurrección de Cristo en sí misma ${ }^{132}$ y no en su exaltación. El relato da cuenta de un contexto dualista de la identidad oculta de Jesús de Nazaret, el Hijo e Hijo del Hombre. Ahora bien, en opinión de diversos autores -H. Kvanvigin,

\footnotetext{
${ }^{129}$ Berger, Theologiegeschichte des Urchristentums, 67.

${ }^{130}$ Carbullanca, "Arrebato", 215-221.

${ }^{131}$ Strecker, Theology of the New Testament, 27; France, The Gospel of Mark, A Commentary on the Greek Text, 342 .

132 Ibíd., 357.

${ }^{133}$ Kvanvig, "The Son of Man in the Parables of Enoch", 214-215.
} 
N. Perrin ${ }^{134}$, M. Smith ${ }^{135}$, O. Walker ${ }^{136}$, E. Schweitzer ${ }^{137}$, y G. Strecker ${ }^{138}$, entre otros-, originariamente la resurrección significó exaltación. Nosotros creemos que se debe matizar y diferenciar.

Como ya hemos mencionado, la escatología judía discrimina estos términos. Moisés, Elías, Esdras, Enoch (1Enoch 1-39), ascienden y están de pie ante el trono de Yahveh, pero no son exaltados, pues arrebato no significa lo mismo que ser exaltado;

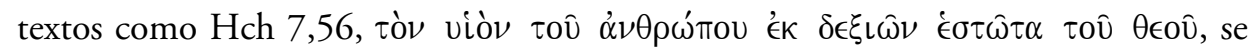
refieren a una cristología que presenta al Hijo del Hombre de pie, delante de Dios (Ap 5,6;7,8).

En cambio, en el caso del Hijo del Hombre de las "Parábolas de Enoch" (70-71), de Moisés de "Exagoge 1", de Enoch (2Enoch 11,1), Metatrón (16, 3) y de Jesús de Nazaret no se menciona tan solo su ascenso sino una transformación y una exaltación a la diestra de Yahveh (Mc 12,36; 14,64; Hch 2,34; 1Co 15,25), con los cuales se subrayan funciones divinas exclusivas de Yahveh en la fe monoteísta, que fueron consideradas una blasfemia en algunos círculos judíos.

\section{Conclusiones y pistas a seguir}

Como ha sido nuestro objetivo, el relato de la transfiguración de Marcos entrega aspectos de una cristología alta que subrayan la autoridad escatológica y gloriosa del Hijo, el Hijo del hombre adámico. Ciertamente -como se ha expuesto-, el relato presupone una cosmovisión de un dualismo cósmico, expresado como la existencia angelomórfica de Elías y Moisés; también expresa la autoridad superior de la identidad de Jesús de Nazaret, identificado como el Hijo por la voz de la nube.

Además, la transformación de Jesús muestra una posible cristología adámica en el Evangelio de Marcos, vinculada a la cuestión de un Hijo del Hombre sacerdotal; así, la transformación de sus vestimentas remite a la convicción de la gloria adámica y a los rasgos sacerdotales del Hijo del Hombre, tal como se puede acreditar en diversos relatos marcanos.

Finalmente, el relato muestra que la condición celeste del Hijo está comprendida dentro del modelo judío del retorno de figuras escatológicas antes del juicio final. Las claves estudiadas en el relato de la transfiguración, junto a los otros textos marcanos

\footnotetext{
${ }^{134}$ Perrin, Rediscovering the Teaching of Jesus, 19.

135 Smith, "Two Ascended to Heaven-Jesus and the Author of 4Q491c", 294.

136 Walker Jr., "Christian Origins and Resurrection Faith", 54.

${ }^{137}$ Schweizer, “The Son of Man”, 124. Véase a Hch 2,36; 13,33; Rm 1,4; 1 Co 12,3; Rm 10.9; 8,34.

${ }^{138}$ Strecker, Theology of the New Testament, 273.
} 
mencionados, son muy significativas, como hemos señalado: de tal modo que la vinculación entre el relato de la transfiguración que muestra al Hijo del Hombre como sumo sacerdote celeste y relatos como Mc 10,45 y 14,61-62 explican el sentido expiatorio que adquirió la entrega de Jesús de Nazaret.

\section{Referencias}

Allison, Dale C. Constructing Jesus: Memory, Imagination, and History. Grand Rapids (MI): Baker Academic, 2013.

Bauckham, Richard. God Crucified. Monotheism and Christology in the New Testament. Carlisle (U. K): Paternoster, 1998.

- Jesus and God of Israel. God Crucified and Other Studies on the New Testament's Christology of Divine Identity. Grand Rapids (MI): William B. Eerdmans Publishing Company, 2008.

. "Monotheism and Christology in the Gospel of John". En Contours of Christology in the New Testament, editado por R. N. Longenecker, 148-166. Grand Rapids (MI): William B. Eerdmans Publishing Company, 2005.

. "Paul's Christology of Divine Identity". The NTS Library, http://www. ntslibrary.com/Pauls\%20Christology\%20of\%20Divine\%20Identity.pdf (consultado el 29 de mayo de 2021).

Berger, Klaus. Formgeschichte des Neuen Testaments. Heidelberg: Quelle \& Meyer, 1984. . Theologiegeschichte des Urchristentums (2nd.ed.). Tübingen: Francke Verlag, 1995.

Boccaccini, Gabriele. I Giudaismi del Secondo Tempio. Da Ezejiele a Daniele. Brescia: Morcelliana, 2008.

Bultmann, Rudolp. Historia de la tradición sinóptica (10. ${ }^{\mathrm{a}}$ ed.). Salamanca: Sígueme, 2000.

Carbullanca César. "Arrebato". En Gran diccionario enciclopédico de la Biblia, editado por A. Ropero, 215-221. Madrid: Clie, 2013.

. "Cristología del Evangelio de Marcos". Theológica Xaveriana 67/184 (2017): 333-359.

- "Muerte de Cristo en el Evangelio de Marcos. Estudio de varias tradiciones del martirio". Gregorianum 100/3 (2019): 463-485. 
. "Orígenes de la cristología del cuarto Evangelio. Un estudio a partir de la tradición de 11QMelquisedec”. Teología y vida 50 (2009): 517-547.

. The Emergence of Suffering Self. A Study about Lists and Social Structures in the Antiquity". Franciscanum 59/167 (2017): 247-275.

Casey Maurice. From Jewish Prophet to Gentile God. Cambridge: James Clark \& Co., 1991.

. "Lord Jesus Christ: A Response to Professor Hurtado". JSNT 27/1 (2004): 83-96.

Catchpole, David. “The Angelic Son of Man in Luke 12:8”. NovT24 (1982): 255-265.

Chester, Andrew. "High Christology-Whence, When and Why?" Early Christianity 2 (2011): 22-50.

. Messiah and Exaltation. Jewish Messianic and Visionary Traditions and New Testament Christology. Tübingen: Mohr Siebeck, 2007.

Collins, Adela. Y. Mark. Minneapolis (MN): Fortress Press, 2007.

Davis, P. G. "Divine agents, mediators, and New Testament Christology". The Journal of Theological Studies 45 (1994): 1-13.

Dibelius, Martin. Die Formgeschichte des Evangeliums. Tübingen: J.C.B. Mohr, 1961.

Dunn, James. Christology in the Making. A New Testament Inquiry into the Origins of the Doctrine of the Incarnation. Philadelphia (PA): Westminster Press, 1980.

. "Messianic Ideas and Their Influence on the Jesus of History". En The Messiah. Developments in Earliest Judaism and Christianity, editado por J. Charlesworth, 37-71. Minneapolis (MN): Minneapolis Press, 2010.

Elior, Rachel. The Three Temples: On the Emergence of Jewish Mysticism. Oxford: The Littman Library of Jewish Civilization, 2004.

Fletcher-Louis, Crispin. "A New Explanation of Christological Origins. A Review of the Work of Larry Hurtado". Tyndale Bulletin 60/2 (2009): 161-205.

. "Jesus as the High Priestly Messiah: Part 1". Journal for the Study of the Historical Jesus 4/2 (2006): 155-175.

. Jesus Monotheism. Vol. 1: Christological Origins: The Emerging Consensus and Beyond. Eugene (OR): Cascade Books, 2015.

. Luke-Acts: Angels, Christology and Soteriology. Tübingen: Mohr Siebeck, 1997. 
France Raymond. T. "Development in New Testament Christology”. Temelios 18 (1992): 4-9.

. The Gospel of Mark, A Commentary on the Greek Text. Grand Rapids (MI): William B. Eerdmans Publishing Company, 2002.

Gathercole, Simon J. The Pre-existent Son: Recovering the Christologies of Matthew, Mark and Luke. Grand Rapids (MI): William B. Eerdmans Publishing Company, 2006.

Gieschen, Charles. Angelomorphic Christology. Antecedents \& Early Evidence. Leiden: Brill, 1998.

Gnilka, Joaquin. El Evangelio de Marcos. Vol. II. Salamanca: Sígueme, 1999.

Grundmann, Walter. Das Evangelium nach Markus. Berlín: Evangelische Verlagsanstalt, 1980.

Hayes, John. "The Resurrection as Enthronement and the Earliest Church Christology". Interpretation 22/3 (1968): 333-345.

Heil, John P. The Transfiguration of Jesus: Narrative Meaning and Function of Mark 9:2-8, Matt 17:1-8 and Luke 9:28-36. Roma: Editrice Pontificio Istituto Biblico, 2000.

Hengel Martin. "Christological Titles in Early Christianity". En The Messiah. Developments in Earliest Judaism and Christianity, editado por J. H. Charlesworth, 425-448. Minneapolis (MN): Fortresss Press, 2010.

Holzmeister, Ulrich. "Einzeluntersuchungen über das Geheimnis der Verkllärung Christi”. Bib 21 (1940): 200-210.

Horsley, Richard. "Jesus-in-context: A Relational Approach”. En Handbook for the Study of the Historical Jesus, editado por Tom Holemn y Stanley Porter, 207-239. Leiden-Boston: Brill, 2001.

Hurtado, Larry. "Early High Christology': A Recent Assessment of Scholarly Debate”. Larry Hurtado's Blog, https://larryhurtado.wordpress.com/2012/12/11/earlyhigh-christology-a-recent-assessment-of-scholarly-debate (consultado el 29 de mayo de 2021).

. "Fashions, Fallacies and Future Prospects in New Testament Studies". Journal for the Study of the New Testament 36/4 (2014): 1-26.

. God in the New Testament. Nashville (TN): Abingdon Press, 2010. 
. How on Earth did Jesus Become a God? Historical Questions about Earliest Devotion to Jesus. Grand Rapids (MI): William B. Eerdmans Publishing Company, 2005.

. One God, One Lord. Early Christian Devotion and Ancient Jewish Monotheism (2 $2^{\text {nd }}$ ed.). Edimburg: T \&T Clark, 1998.

. Señor Jesucristo. La devoción a Jesús en el cristianismo primitivo. Salamanca: Sígueme, 2008.

Jeremias, Joaquim. Theology of New Testament. London: SCM Press, 1971.

Johansson, Daniel. "Jesus and God in the Gospel of Mark: Unity and Distinction". A thesis presented for the degree of $\mathrm{PhD}$ at the University of Edinburgh, 2011.

Kirk, J. R. Daniel A Man Attested by God: The Human Jesus of the Synoptic Gospels. Grand Rapids (MI): William B. Eerdmans Publishing Company, 2016.

. "Daniel. Mark's Son of Man and Paul's Second of Adam". Horizons in Biblical Theology 37 (2015): 170-195.

Koch, Klaus. "Questions Regarding the So-called Son of Man in the Parables of Enoch: A Response to Sabino Chiala and Helge Kvanvig”. En Enoch and the Messiah Son of Man, editado por G. Boccaccini, 236-237. Grand Rapids (MI): William B. Eerdmanns Publishing Company, 2007.

Kok, Michael. "Marking a Difference: The Gospel of Mark and the 'Early High Christology' Paradigm”. JMJS 3 (2016): 102-124.

Kremer, Jacob. "opóa”. En Diccionario exegético del Nuevo Testamento, editado por Horst Balz y Gerhard Schneider, II, 581-588. Salamanca: Sígueme, 1998.

Kvanvig, Helge. "The Son of Man in the Parables of Enoch". En Enoch and the Messiah Son of Man, editado por G. Boccaccini, 214-215. Grand Rapids (MI): William B. Eerdmanns Publishing Company, 2007.

Loader, W. R. "The Apocalyptic Model of Sonship: Its Origin and Development in New Testament Tradition”. JBL 97/4 (1978): 525-554.

Lohmeyer, Eduard. "Die Verklärung Jesu nach dem Markus-evangelium”. ZNW 21 (1922): 185-215.

Marcus, Joel. El Evangelio de Marcos (Mc 8-16). Salamanca: Sígueme, 2011. . Mark 1-8. A New Translation with Introduction and Commentary. New Haven \& London: Doubleday \& Co., 2002. 
. Mark 8-16. A New Translation with Introduction and Commentary. New Haven \& London: Doubleday \& Co., 2009.

Michaelis, Wilhelm. "opód $\omega$ ". En Theological Dictionary of the New Testament, editado por G. Kittel y G. Friedrich V, 814-823. Grand Rapids (MI): William B. Eerdmans Publishing Company, 1967.

Müller Ulrich. "Die Christologische Absicht des Markusevangeliums und die Verklärungsgeschichte". Zeitschrift für die Neutestamentliche Wissenschaft 64 (1973): 60-61.

Naizer, Eric R. "Adam, Humanity, and Angels: Early Jewish Conceptions of the Elect and Humankind Based on Genesis 1-3". Doctoral Dissertation. The Florida State University, College of Arts and Sciences, 2013.

Neusner, Jacob. The Judaism the Rabbis Take for Granted. Atlanta (GA): Scholars Press, 1994.

Öhler, Marcus. "Die Verklarung (Mk 9,1-8): Die Ankunft der Herrschaft gotters auf der erde”. Novum Testamentum XXXVIII/3 (1996): 197-217.

Orlov, Andrew. "Moses' Heavenly Counterpart in the Book of Jubilees and the Exagoge of Ezekiel the Tragedian”. Biblica 88/2 (2007): 153-173.

Parkman, Joel W. "Adam Christological Motifs in the Synoptic Traditions". Thesis (PhD.), Baylor University, Waco (TX), 1994.

Perrin, Nicholas. "Jesus as Priest in the Gospels". SBJT 22/2 (2018): 81-99.

Perrin, Norman. Rediscovering the Teaching of Jesus. New York (NY): Harper \& Row Publishers, 1976.

Pesch, Rudolp. Das markusevangelium. Vols. I-II. Freiburg: Herder, 1976-1977. . "La genese de la foi en la resurrection de Jésus". En La Paque du Christ Mystere de salut, editado por M. Benerat, A. Schmid y J. Guillet, 51-74. Paris: Les Editions du Cerf, 1982.

. "Zur entstehung des Glaubens an die Auferstehungen Jesu. Ein Vorschlag zur Diskussion”. ThQ 153 (1973): 201-228.

Pesch R. y R. Schnackenburg (eds.) Jesus und der Menschensohn. Freiburg: Herder, 1975.

Robinson, John A. T. “The Most Primitive Christology of All?” The Journal of Theological Studies 7/2 (1956): 177-189.

Rowland, Christopher. The Open Heaven: A Study of Apocalyptic in Judaism, and Early Christianity. New York (NY): Crossroad, 1982. 
Rowland, Christopher, y Christopher R. A. Morray-Jones. The Mystery of God. Early Jewish and the New Testament. Leiden: Brill, 2009.

Sacchi, Paolo. La historia del judaismo en la época del segundo Templo. Madrid: Trotta, 2004.

Schiavo Luigi. Anjos e Messias. Mesianismo judaicos e origen da cristología. Sao Paulo: Paulinas, 2006.

Schmithals, Walter. "Der Markusschluß, die Verklarungsgeschichte und die Aussendung der Zwölf”. ZThK 69 (1972): 379-411.

Schweizer, Eduard. Das evangelium Markus. Göttingen: Vandenhoeck \& Ruprecht, 1968.

. "The Son of Man". Journal of Biblical Literature 79/2 (1960): 119-129.

Segal, Alan. Two Powers in Heaven: Early Rabbinic Reports about Christianity and Gnosticism. Leiden: Brill, 1977.

Smith, Morton. "Two Ascended to Heaven-Jesus and the Author of 4Q491c". En Jesus and the Dead Sea Scrolls, editado por J. Charlesworth, 290-301. New York: Doubleday, 1992.

Steenburg, D. "The Worship of Adam and Christ as Imagen of God". JSNT 39 (1990): 479-505.

Strecker, George. Theology of the New Testament. New York-Berlin: Wesminster John Knox Press, 2000.

Sullivan, K. Wrestling with Angels. A Study of the Relationship between Angels and Humans in Ancient Jewish Literature and the New Testament. Boston-Leiden: Brill, 2004.

Talbert, Charles H. "The Problem of Pre-Existence in Philippians 2:6-11". Journal of Biblical Literature 86/2 (1967): 141-153.

Taylor, Vincent. El Evangelio de Marcos. Madrid: Cristiandad, 1979.

Tuschling, Ruth M. Angels and Orthodoy. A Study in their Development in Syria and Palestine from Qumran Texts to Ephrem the Syrian. Tübingen: Mohr Siebeck, 2007.

Theissen Gerd. A Theory of Primitive Christian Religion. London: SCM Press, 1999. . El Jesús histórico. Sígueme: Salamanca, 2000. 
Throup, Marcus. “Mark's Jesus, Divine? A Study of Aspects of Mark's Christology with Special Reference to Hebrew Divine Warrior Traditions in Mark, and in Relation to Contemporary Debates on Primitive Christology". PhD thesis, University of Nottingham, 2014.

Vanderkam, James. "Richteous One, Messiah, Chosen one, and the Son of Man in 1Enoch 37-71". En The Messiah. Developments in Earliest Judaism and Christianity, editado por J. H. Charlesworth, 183-184. Mineapolis (MN): Fortresss Press, 2010.

Vielhauer, Philip. Historia de la literatura cristiana primitiva. Salamanca: Sígueme, 1981.

Vögtle, Anton y R. Pesch. Wie kam es zum Osterglauben. Dusseldorf: Patmos Verlag, 1975.

Walker Jr., William O. "Christian Origins and Resurrection Faith". The Journal of Religion 52/1 (1972): 41-55.

Watts, R. E. The Influence of the Isaianic New Exodus on the Gospel of Mark. Tübingen: Mohr Siebeck, 1997.

Watts, H. S. Christology and Discipleship in the Gospel of Mark. Cambridge: Cambridge University Press, 2006.

Wilkens, Ulrich. Resurrection. Atlanta (GA): John Knox Press, 1978.

Yarbro, Adela. Cosmology and Eschatology in Jewish and Christian Apocalypticism. Leiden: Brill, 1996. 